\title{
Second-generation non-invasive high-throughput DNA sequencing technology in the screening of Down's syndrome in advanced maternal age women
}

\author{
JIAO ZHANG and BIN ZHANG \\ Obstetrics Department, Obstetrics and Gynecology Hospital of Fudan University, Shanghai 200011, P.R. China
}

Received August 13, 2015; Accepted January 27, 2016

DOI: $10.3892 /$ br.2016.653

\begin{abstract}
The aim of the present study was to evaluate the efficacy of using non-invasive DNA testing technology in screening Down's syndrome among women of advanced maternal age (AMA) and to provide evidence for prenatal screening of Down's syndrome. With a double-blind design, $8 \mathrm{ml}$ of peripheral venous blood samples were collected from 87 women aged $\geq 35$ years after 12 weeks of pregnancy. All cases were recorded with unique identification cards with clinical details and followed up until delivery. All the non-invasive prenatal testing results were confirmed by amniotic fluid fetal karyotyping (the gold standard of aneuploidy test), follow-up examination by neonatologists or neonatal blood karyotyping. The sensitivity, specificity and other indicators of non-invasive DNA testing technology were calculated based on the data of 87 women of AMA. Among the 87 women of AMA, 5 were cases with abnormal numbers of chromosomes (3 cases of trisomy 21,1 case of trisomy 18 and 1 case of 47, XXX). The sensitivity and specificity reached $100 \%$ for trisomy 21 , trisomy 18 and 47, XXX. The present study supports that non-invasive DNA testing is a useful method of AMA screening of Down's syndrome with $100 \%$ accuracy. Therefore, it can be used as an important alternative screening method for Down's syndrome in women of AMA.
\end{abstract}

\section{Introduction}

Non-invasive analysis of fetal genetic traits via material blood has been commonly used for the prenatal diagnosis of Down's syndrome (1). Such detection is initially promising; however, a large majority of examinations using fetal cells enriched from maternal blood have reduced due to the scarcity of the cells (2). In 1997, Lo et al (3) reported the presence of fetal

Correspondence to: Professor Bin Zhang, Obstetrics Department, Obstetrics and Gynecology Hospital of Fudan University, 419 Fangxie Road, Shanghai 200011, P.R. China

E-mail: shenutzhangbin@163.com

Key words: advanced maternal age, Down syndrome, non-invasive DNA testing
DNA in maternal blood for the first time. Following this, the non-invasive prenatal test (NIPT) was initially conducted through sequencing technique $(4,5)$. Compared to other genotyping technology, DNA sequencing has a higher accuracy, and can detect new mutations effectively. Even though the first-generation traditional Sanger sequencing technology is already highly automated, the sequencing throughput is low as a larger DNA fragment cannot be quickly sequenced.

The second-generation high-throughput sequencing technology is a breakthrough with high-throughput sequencing and shorter test cycles. The high-throughput sequencing overcomes the limit of gene chip technology, which is unable to identify a new gene. As the high-throughput sequencing technology has only been established recently, it has not yet reached its full development potential. This technology can only store extremely limited transcriptome information. In the past decades, next-generation sequencing (NGS) technology has been developed, and its experimental techniques and post-data analysis theory have matured and accumulated a huge public database. Therefore, NGS technology remains the dominant technology. However, we believe that in the near future, high-throughput sequencing technology will be improved and be more widely used. Second-generation high-throughput DNA sequencing technology is gaining increasing attention and is expected to become one of the preferred options of prenatal screening for Down's syndrome.

In the present study, the use of non-invasive DNA testing technology for the screening of Down's syndrome was evaluated in Chinese advanced maternal age (AMA) women.

\section{Materials and methods}

Participants. In total, 87 women of AMA who received prenatal screening between January 2012 and December 2013 at the Obstetrics and Gynecology Hospital of Fudan University (Shanghai, China) were enrolled in the study. The inclusion criteria were as follows: i) Aged $\geq 35$ years at the time of delivery; ii) single birth; iii) high risk of Down's syndrome or single abnormal multiple of the median; iv) elevated fetal nuchal translucency (NT) in the early pregnancy, a soft marker in the genetic scan, or cardiac structural abnormalities in the second-trimester genetic sonography; v) not suitable for invasive prenatal diagnosis, such as those with human immunodeficiency virus infection, placenta previa, low-set 
placenta, oligohydramnios, Rh-negative blood type, a history of abortion, threatened abortion or precious pregnancy. Those with chromosomal diseases, or received allogeneic blood transfusion, organ transplantation, stem cell therapy, or with a gestational age of $<12$ weeks were excluded from the study. Written informed consent was obtained from each participant. The protocols were approved by the Ethics Committee of the Obstetrics and Gynecology Hospital of Fudan University.

Measurements. Peripheral blood $(8 \mathrm{ml})$ was collected from each participant 12 weeks after pregnancy. High-throughput sequencing was performed using the 12-plex Hiseq 2000 platform (Berry and Kang Biotechnology Co., Ltd., Beijing, China) by personnel who were blinded to the study. All the NIPT results were confirmed by the gold standard of aneuploidy test-amniotic fluid fetal karyotyping, follow-up examination by neonatologists or neonatal blood karyotyping. Hospital records for each participant were available with detailed clinical data and they were follow-up until delivery.

Non-invasive DNA second-generation high-throughput sequencing technology. Illumina (Solexa, San Diego, CA, USA) sequencing was adopted in the non-invasive DNA second-generation high-throughput sequencing using the sequence by synthesis method (6-8). Briefly, maternal blood $(8 \mathrm{ml})$ was collected in EDTA and anticoagulant tubes. The samples were centrifuged at $1,600 \mathrm{x}$ g for $10 \mathrm{~min}$ at $4^{\circ} \mathrm{C}$. Subsequently, the supernatant was transferred to centrifuge tubes, followed by centrifugation at $16,000 \mathrm{x} \mathrm{g}$ for $10 \mathrm{~min}$ at $4^{\circ} \mathrm{C}$ to obtain the plasma.

DNA extraction was performed using the magnetic bead separation technique using a Tecan Genesis Workstation RSP 150 instrument (Tecan Germany, Crailsheim, Germany), according to the manufacturer's protocol (9). PCR amplifications were performed in a total volume of $50 \mu \mathrm{l}$ containing $22 \mu \mathrm{l}$ DNA, $25 \mu$ l Phusion DNA polymerase and $1 \mu \mathrm{l}$ of each PCR primer under the following conditions: Predenaturation at $98^{\circ} \mathrm{C}$ for $30 \mathrm{sec}$, followed by 15 cycles of denaturation at $98^{\circ} \mathrm{C}$ for $10 \mathrm{sec}$, annealing at $65^{\circ} \mathrm{C}$ for $30 \mathrm{sec}$ and extension at $72^{\circ} \mathrm{C}$ for $30 \mathrm{sec}$. Finally, the samples were extended at $72^{\circ} \mathrm{C}$ for $5 \mathrm{~min}$.

Statistical analysis. Burrows-Wheeler Aligner software (10) was used to compare the sample sequences to the human genome reference sequence. BGPD v2.0.1 software was used to calculate each chromosome sequence statistics. Z-score of the proportion of each chromosome (\% chrN) was calculated as:

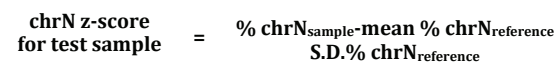

The actual prevalence of samples was assessed by $Z$ values (cutoff: $\mathrm{Z}=3$ ). The sensitivity, specificity and other indicators of non-invasive DNA detection technology were calculated using SPSS 16.0 software (SPSS, Inc., Chicago, IL, USA).

\section{Results}

Participant characteristics. A total of 87 women (37.48 \pm 2.17 years) of AMA who had a single birth received prenatal screening between January 2012 and December 2013
Table I. Demographic information.

\begin{tabular}{lc}
\hline Screening & Positive screening, \% (no. positive/total) \\
\hline Serological & $45.2(19 / 42)$ \\
Sonography & $16.0(13 / 81)$ \\
\hline
\end{tabular}

Table II. Karyotype analysis.

\begin{tabular}{lcc}
\hline Karyotype & $\begin{array}{c}\text { Non-invasive } \\
\text { DNA testing, } \mathrm{n}(\%)\end{array}$ & Amniocentesis, n (\%) \\
\hline Trisomy 21 & $3(3.45)$ & $3(3.45)$ \\
Trisomy 18 & $1(1.15)$ & $1(1.15)$ \\
47, XXX & $1(1.15)$ & $1(1.15)$ \\
$45, \mathrm{X}$ & $1(1.15)$ & $0(0.00)$ \\
Normal & $81(93.10)$ & $82(94.25)$ \\
\hline
\end{tabular}

at the Obstetrics and Gynecology Hospital of Fudan University were included in the study. The median gestational age at the time of blood collection was 19.0 weeks (12.4-32.5 weeks). Amniocentesis was performed in $24.1 \%$ (21/87) of the participants. A total of 42 participants received serological screening, among which 19 exhibited positive results. A total of 81 received sonography screening, and 13 exhibited positive results. The demographic information of the participants is listed in Table I.

Karyotyping analysis. Karyotyping abnormalities were identified in 5 cases $(6.2 \%)$ using the amniocentesis, including trisomy $21(n=3)$, trisomy $18(n=1)$, and $47, X X X(n=1)$. However, a false-negative sample with a katyotype of $45, \mathrm{X}$ was identified using the non-invasive DNA testing technology in addition to the karyotyping abnormalities using the amniocentesis (Table II).

Evaluation results of non-invasive DNA testing technology. Table III summarizes the sensitivity and specificity of the non-invasive DNA testing technology. These results indicated an accuracy and specificity of $100 \%$ for the non-invasive DNA testing of AMA for trisomy 21, trisomy 18 and 47, XXX, respectively.

$Z$-score results of chromosome 21 . In the present study, the $\mathrm{Z}$-score of chromosome 21 in all the cases was determined. The results indicated that the $Z$ values were $\geq 3$ in the 3 cases of trisomy 21 , which was significantly different compared with those of the non-Down's syndrome cases $(\mathrm{P}<0.05)$ (Fig. 1).

\section{Discussion}

Down's syndrome is one of the most common fetal chromosomal abnormalities worldwide. In China, children with Down's syndrome are entitled to disability benefits and a pension, which places a huge economic burden on the family and society. 
Table III. Evaluation of non-invasive DNA testing technology.

Positive, \% (no. positive/total)

\begin{tabular}{llllc}
\cline { 2 - 4 } Variable & Trisomy 21 & Trisomy 18 & 47, XXX & 45, X \\
\hline Sensitivity & $100(3 / 3)$ & $100(1 / 1)$ & $100(1 / 1)$ & N/A \\
Specificity & $100(84 / 84)$ & $100(86 / 86)$ & $100(86 / 86)$ & $99(86 / 87)$ \\
Positive predictive value & $100(3 / 3)$ & $100(1 / 1)$ & $100(1 / 1)$ & N/A \\
Negative predictive value & $100(84 / 84)$ & $100(86 / 86)$ & $100(86 / 86)$ & $100(86 / 86)$ \\
\hline
\end{tabular}

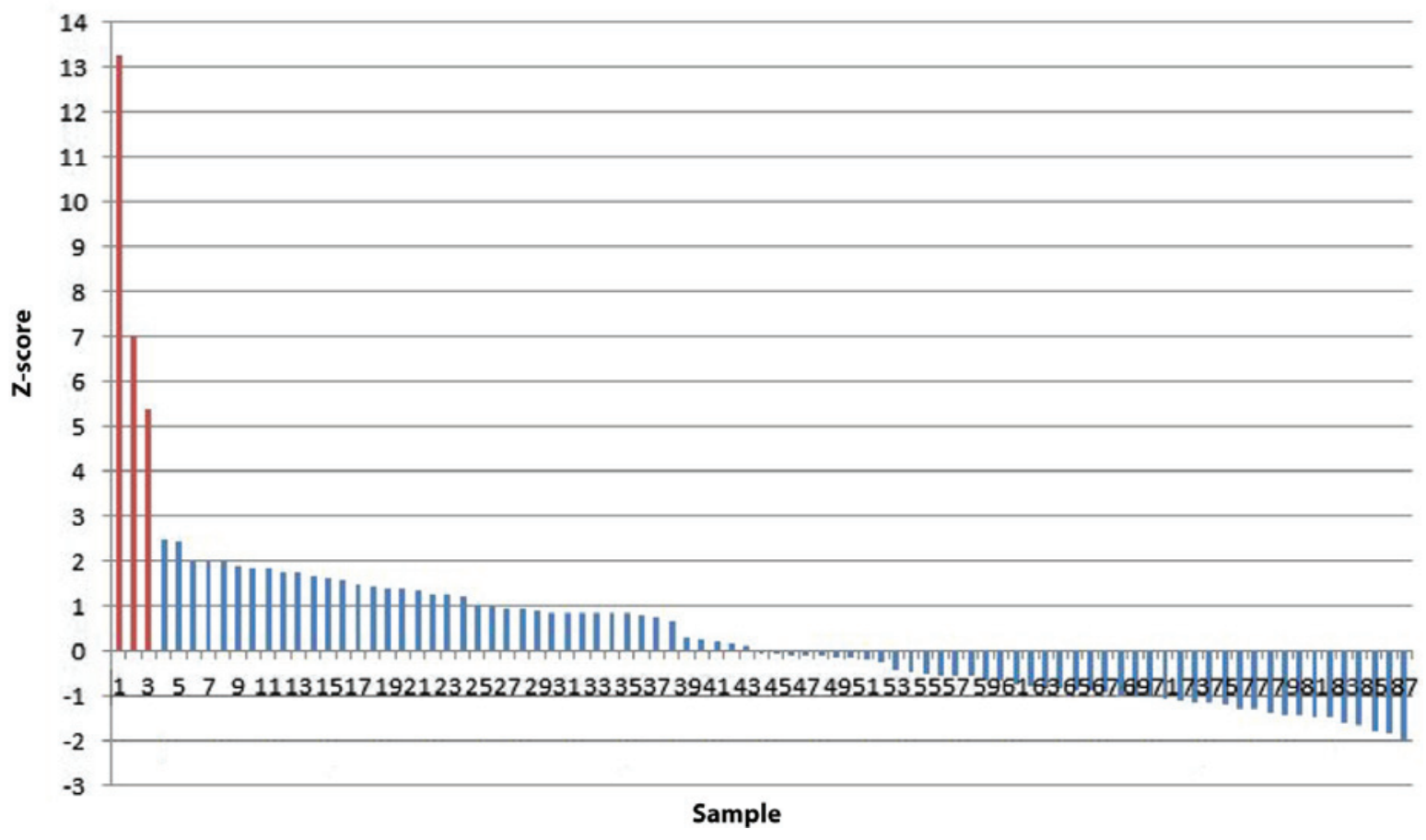

Figure 1. Z-scores of chromosome 21 in all cases. The red bars indicate Down's syndrome; the cut-off value of trisomy 21 is 3 .

In the past two decades, NIPT for aneuploidy using cell-free DNA in maternal plasma has been considered as a revolutionary prenatal screening and diagnostic method. In 1997, Lo (11) initially discovered cell-free fetal DNA in maternal plasma, which allowed novel possibilities for the non-invasive prenatal screening and diagnosis. Non-invasive prenatal diagnosis of trisomy 21 has been well-acknowledged using the methylated DNA immunoprecipitation technique, as the cell-free fetal DNA fragments were extensively methylated (12). To the best of our knowledge, a relative amount of free DNA of chromosome 21 was detected in the maternal plasma in the fetus with Down's syndrome compared to reference chromosomes. These subtle changes may be accurately detected by high-throughput sequencing technology.

In the present study, 87 women of AMA were included, and an accuracy and specificity of $100 \%$ was obtained for the screening of trisomy 21 using non-invasive DNA testing. On this basis, it is reasonable to speculate that this new technology is effective for the prenatal screening of Down's syndrome, and may be served as the first-line choice. Despite the good sensitivity and accuracy of such a technique, there remain limitations in the study. The sample size was small, which does not represent the whole population. In the future, studies with larger sample sizes are required to investigate the sensitivity and specificity of non-invasive second-generation high-throughput DNA testing technology for the screening of trisomy 21.

An increasing number of studies have shown that cell-free fetal DNA in maternal blood is an indicator for the detection rate of trisomy 21 , trisomy 18 and trisomy 13 , which were $\geq 99,97$ and $79 \%$, respectively, while the corresponding false-positive rate of aneuploidy for each were $0.1,0.1$ and $0.4 \%$, respectively. In those studies, the averaged age of pregnant women was 33.5-37 years, and the averaged maternal age of patients with trisomy 21 was 35.4-39.6 years. Among these cases, the majority $(68.3 \%)$ of women were of AMA, and $36.8 \%$ of them were $>38$ years (13-16). In addition, Chiu et al (17) reported that the Z-score of chromosome 21 in pregnant women with trisomy 21 fetuses was significantly higher than those of the normal control. To the best of our knowledge, the second-generation sequencing technology was initially used for the non-invasive prenatal screening in a previous study (18). In the study, all 9 cases of trisomy 21 (Down's syndrome), 2 cases of trisomy 18 (Edwards' syndrome) 
and 1 case of trisomy 13 (Patau syndrome) were identified in a cohort of 18 normal and aneuploid pregnancies. Thus far, the largest clinical trial carried out the largest international clinical study, which included 212 cases of trisomy 21-positive pregnant women and 1,484 cases of negative samples of trisomy 21 (19). They obtained the accuracy rate of $98.6 \%$ $(209 / 212)$ and a false-positive rate of $0.20 \%$. However, the sensitivity and specificity of non-invasive prenatal detection of trisomy 21, trisomy 18 and trisomy 13 did not achieve $100 \%$. Therefore, it should not be used as a diagnostic test to replace invasive diagnosis in high-risk pregnant women, but as a screening tool to guide further diagnosis (20).

In the present study, cell-free fetal DNA second-generation sequencing technology showed the following advantages for the prenatal screening. Firstly, a high detection rate and a low false-positive rate were identified to the target disease. Secondly, it is suitable to a wide gestational age range, such as early pregnancy, middle pregnancy, and even after 23 weeks of pregnancy. Thirdly, the process is relatively simple and quality control is easy. Finally, it can effectively reduce the number of prenatal invasive diagnosis. However, such a technique is not suitable for the prenatal screening of multiple births, chimeras and parents with chromosome abnormalities.

In conclusion, the non-invasive prenatal screening of trisomy 21 in women of AMA with higher sensitivity, specificity and accuracy is superior to the commonly used method based on maternal age, fetal ultrasound and maternal serum biochemistry. In particular, such technology will reduce the invasive procedures, and eliminate the associated risks in women with a high-risk of giving birth to a baby with trisomy 21 and were not suitable for invasive prenatal diagnosis. In the future, cell-free fetal DNA testing is expected to be an effective screening method for Down's syndrome in AMA women.

\section{References}

1. Lo YMD, Chiu RWK, Chan KCA and Chung GTY: Free fetal DNA in maternal circulation. JAMA 292: 2835-2836, 2004.

2. Hahn S, Zhong XY and Holzgreve W: Recent progress in non-invasive prenatal diagnosis. Semin Fetal Neonatal Med 13: $57-62,2008$

3. Lo YM, Corbetta N, Chamberlain PF, Rai V, Sargent IL, Redman CW and Wainscoat JS: Presence of fetal DNA in maternal plasma and serum. Lancet 350: 485-487, 1997.

4. Lo YM, Tsui NB, Chiu RW, Lau TK, Leung TN, Heung MM, Gerovassili A, Jin Y, Nicolaides KH, Cantor CR and Ding C: Plasma placental RNA allelic ratio permits noninvasive prenatal chromosomal aneuploidy detection. Nat Med 13: 218-223, 2007.
5. Chiu RW, Cantor CR and Lo YM: Non-invasive prenatal diagnosis by single molecule counting technologies. Trends Genet 25: 324-331, 2009.

6. Fedurco M, Romieu A, Williams S, Lawrence I and Turcatti G: BTA, a novel reagent for DNA attachment on glass and efficient generation of solid-phase amplified DNA colonies. Nucleic Acids Res 34: e22, 2006.

7. Turcatti G, Romieu A, Fedurco M and Tairi AP: A new class of cleavable fluorescent nucleotides: Synthesis and optimization as reversible terminators for DNA sequencing by synthesis. Nucleic Acids Res 36: e25, 2008.

8. Mardis ER: The impact of next-generation sequencing technology on genetics. Trends Genet 24: 133-141, 2008.

9. Pichl L, Heitmann A, Herzog P, Oster J, Smets H and Schottstedt V: Magnetic bead technology in viral RNA and DNA extraction from plasma minipools. Transfusion 45: 1106-1110, 2005.

10. Li H and Durbin R: Fast and accurate short read alignment with Burrows-Wheeler Transform. Bioinformatics 25: 1754-1760, 2009.

11. Lo YM: Recent advances in fetal nucleic acids in maternal plasma. J Histochem Cytochem 53: 293-296, 2005.

12. Papageorgiou EA, Karagrigoriou A, Tsaliki E, Velissariou V, Carter NP and Patsalis PC: Fetal-specific DNA methylation ratio permits noninvasive prenatal diagnosis of trisomy 21 . Nat Med 17: 510-513, 2011.

13. Ehrich M, Deciu C, Zwiefelhofer T, Tynan JA, Cagasan L, Tim R, Lu V, McCullough R, McCarthy E, Nygren AO, et al: Noninvasive detection of fetal trisomy 21 by sequencing of DNA in maternal blood: A study in a clinical setting. Am J Obstet Gynecol 204: e1-e11, 2011.

14. Palomaki GE, Kloza EM, Lambert-Messerlian GM, Haddow JE, Neveux LM, Ehrich M, van den Boom D, Bombard AT, Deciu C, Grody WW, et al: DNA sequencing of maternal plasma to detect down syndrome: An international clinical validation study. Genet Med 13: 913-920, 2011.

15. Sparks AB, Struble CA, Wang ET, Song K and Oliphant A: Noninvasive prenatal detection and selective analysis of cell-free DNA obtained from maternal blood: Evaluation for trisomy 21 and trisomy 18. Am J Obstet Gynecol 206: e1-e9, 2012.

16. Nicolaides KH, Syngelaki A, Ashoor G, Birdir C and Touzet G: Noninvasive prenatal testing for fetal trisomies in a routinely screened first-trimester population. Am J Obstet Gynecol 207: e1-e6, 2012.

17. Chiu RW, Chan KC, Gao Y, Lau VY, Zheng W, Leung TY, Foo CH, Xie B, Tsui NB, Lun FM, et al: Noninvasive prenatal diagnosis of fetal chromosomal aneuploidy by massively parallel genomic sequencing of DNA in maternal plasma. Proc Natl Acad Sci USA 105: 20458-20463, 2008.

18. Fan HC, Blumenfeld YJ, Chitkara U, Hudgins L and Quake SR: Noninvasive diagnosis of fetal aneuploidy by shotgun sequencing DNA from maternal blood. Proc Natl Acad Sci USA 105: 16266-16271, 2008.

19. Bianchi DW, Platt LD, Goldberg JD, Abuhamad AZ, Sehnert AJ and Rava RP: Genome-wide fetal aneuploidy detection by maternal plasma DNA sequencing. Obstet Gynecol 119: 890-901, 2012.

20. Ashoor G, Syngelaki A, Wang E, Struble C, Oliphant A, Song K and Nicolaides KH: Trisomy 13 detection in the first trimester of pregnancy using a chromosome-selective cell-free DNA analysis method. Ultrasound Obstet Gynecol 41: 21-25, 2013. 